\title{
Super strong 2D titanium carbide MXene-based materials: a theoretical prediction
}

\author{
Seyedeh Alieh Kazemi, and Yun Wang* \\ Centre for Clean Environment and Energy, School of Environment and Science, Griffith University, \\ Gold Coast Campus, QLD 4222, Australia
}

* Authors to whom correspondence should be addressed

E-mail: yun.wang@griffith.edu.au

\begin{abstract}
The discovery of strong materials is essential in materials science and engineering. It becomes more significant to the practical applications of two-dimensional (2D) materials. In this study, the mechanical properties of all known 2D titanium carbide-based MXene monolayers have been systematically investigated by means of the density functional theory computations. Both the impacts of the thickness of the MXenes and the surface functionalization have been considered. Our results reveal that the in-plane planar elastic constants, Young's moduli and Shear moduli increase over the thickness. Moreover, they are enhanced by the terminal groups of surface functionalization. And the oxygen terminal group has the largest influence. As a result, the $2 \mathrm{D} \mathrm{Ti}_{4} \mathrm{C}_{3} \mathrm{O}_{2}$ is the strongest one among all $2 \mathrm{D}$ titanium carbide-based MXene, which is even stronger than the graphene. Our prediction provides the theoretical foundation for the specific application of MXenes that demands superior mechanical properties.
\end{abstract}

KEYWORDS. Titanium carbide MXenes, Super Strong 2D Materials, Young's Modulus, surface functionalization, DFT computations 
Mechanical properties of two dimensional (2D) materials are essential for their applications since they determine their stiffness and stability [1-3]. The 2D materials with superior mechanical properties, e.g. graphene with the bulk Young's modules of about $1 \mathrm{TPa}$, can be promising candidates as composite materials, protective coatings, fibers and energy storage materials [4]. To this end, numerous studies have been devoted to discovering strong $2 \mathrm{D}$ materials. A recent study by Lipatov et al. experimentally demonstrates that the $2 \mathrm{D} \mathrm{Ti}_{3} \mathrm{C}_{2} \mathrm{~T}_{\mathrm{x}}$ MXene monolayer is a novel strong 2D material, which possess the similar in-plane planar Young's modulus of graphene. This work paved the avenue to search other strong 2D MXene monolayer for the similar applications. MXenes is a new family of 2D transition metal carbides and carbonitrides with more than 70 known species, which can be synthesized by the exfoliation of MAX phases [5, 6]. MXenes have a general formula of $M_{n+1} X_{n}$, where $M$ and X represent a metal and $\mathrm{C} / \mathrm{N}$, respectively. Whereas, $\mathrm{n}$ can be 1,2 , or 3 in the known MXene materials [5]. In practicality, MXenes are too chemically active, which can be synthesized through the surface functionalization using terminal groups including $-\mathrm{OH},-\mathrm{O}$ and $-\mathrm{F}$. The terminal groups are termed as T. As such, the surface functionalized MXenes are labelled as $M_{n+1} X_{n} T_{x}$ [7, 8]. The surface functionalized MXenes have further led to numerous technological applications, e.g. energy storage [9, 10], electromagnetic interference shielding,[11, 12] composite materials [13], catalysts [14] and sensors [15]. While the structural and electronic properties of $\mathrm{M}_{\mathrm{n}+1} \mathrm{X}_{\mathrm{n}} \mathrm{T}_{\mathrm{x}}$ have been widely investigated $[12,16]$, their mechanical properties have not been systematically studied in detail due to the novelty of these materials.

Most previous studies of the mechanical properties of $2 \mathrm{D} \mathrm{M}_{\mathrm{n}+1} \mathrm{X}_{\mathrm{n}} \mathrm{T}_{\mathrm{x}}$ are based on the first-principles density functional theory (DFT) calculations. This is because of the big challenge to synthesize high-quality large 2D single crystals for experimentally measurements $[17,18]$. Additionally, the DFT calculations have the demonstrated capability to reproduce the mechanical properties of materials obtained from the experiments [4]. As such, the DFT simulation becomes a promising alternative approach to investigate the mechanical properties of materials. In 2012, a large elastic constant $\left(C_{11}\right)$ of some Ti-based carbides MXenes have been theoretically revealed based on the DFT calculations, which indicate that the $\operatorname{Ti}_{n+1} X_{n}$ may be a promising 2D compositional material [19]. In 2014, Wang et al. got the similar conclusions through DFT calculations of the elastic properties of $\mathrm{Ti}_{2} \mathrm{C}$ monolayer [20]. Later, Fu et al. predicted that the surface functionalization can remarkably improve the Young's modulus and shear modulus of $\mathrm{Ti}_{3} \mathrm{C}_{2}$ [21], which was experimentally confirmed by a recent experimental 
work conducted by Lipatov et al. [22]. However, the impact of surface functionalization on $\mathrm{Ti}_{2} \mathrm{C}$ and $\mathrm{Ti}_{4} \mathrm{C}_{3}$ are largely unknown. To obtain the holistic picture about the mechanical properties of surface functionalized $2 \mathrm{D} \mathrm{Ti} \mathrm{i}_{n+1} \mathrm{C}_{\mathrm{n}}(\mathrm{n}=1,2$ or 3$)$, the DFT method is employed to calculate their lattice parameter, in-plane planar elastic constant $\mathrm{C}_{\mathrm{ij}}$, in-plane planar Young's modulus $E^{2 D}$ in x and y direction, in-plane planar shear modulus $G_{x y}^{2 D}$, and Poisson's ratio $v$ in $x$ and $y$ direction. Our results suggest $2 \mathrm{D} \mathrm{Ti}_{4} \mathrm{C}_{3} \mathrm{O}_{2}$ are the strongest materials among all the systems considered here, which in-plane planar Young's modulus is $48 \%$ higher than that of graphene [23].

The structural, mechanical and electronic properties are calculated using the DFT as implemented in the Vienna $a b$ initio simulation package (VASP) [24]. Electron- ion interactions were described using standard PAW potentials [25], with valence configurations of $3 s^{2} 3 p^{6} 4 s^{2} 3 d^{2}$ for $\mathrm{Ti}, 2 s^{2} 2 p^{2}$ for $\mathrm{C}, 2 \mathrm{~s}^{2} 3 \mathrm{p}^{4}$ for $\mathrm{O}$ and $1 \mathrm{~s}^{1}$ for $\mathrm{H}$. The generalized gradient approximation (GGA) with the format of Perdew-Burke-Ernzehof (PBE) was applied for the exchange-correlation functional [26]. Since traditional DFT calculations at the PBE level cannot correctly include the nonlocal van der Waals interactions [27], the calculations with dispersion corrections may affect the adsorption energies of small molecules [28]. In this regard, the DFT-D3 method was used for dispersion corrections here [29]. A plane-wave basis set with the cut-off kinetic energy of $520 \mathrm{eV}$ is used. The Monkhorst-Pack k-point meshes with a reciprocal space resolution of $2 \pi \times 0.04 \AA^{-1}$ were utilized for structural optimization and static self-consistent calculations of $\mathrm{Ti}_{n+1} \mathrm{C}_{\mathrm{n}} \mathrm{T}_{2}$ monolayers. All the atoms were allowed to relax until the Hellmann-Feynman forces were smaller than $0.02 \mathrm{eV} / \AA$. The convergence criterion for the self-consistent electronic optimization loop was set to $1 \times 10^{-5} \mathrm{eV}$. To calculate the elastic constants of the MXene according to generalized Hooke’s law, the energies as a function of strain $(\varepsilon)$ in the strain range $-2.0 \% \leq \varepsilon \leq 2.0 \%$ with increment of $0.5 \%$ were calculated. The elastic constants $\mathrm{C}_{\mathrm{ij}}$ were obtained by fitting a second-order polynomial to the change in the total energy versus applied strain by post-processing the VASP calculated data using the VASPKIT code (see Supplementary Material) [30, 31]. A spin-polarization calculation on $\mathrm{Ti}_{4} \mathrm{C}_{3} \mathrm{O}_{2}$ was conducted, which revealed that the system was non-magnetic. As such, the nonspin polarization DFT calculations were performed throughout in this study. The $\mathrm{Ti}_{4} \mathrm{C}_{3} \mathrm{O}_{2}$ system was also used to do the convergence test about the mechanical properties in terms to vacuum thickness, which demonstrated that a vacuum thickness of $15 \AA$ is required (see Table S1). To ensure the vacuum was thick enough to avoid the interaction between $2 \mathrm{D}$ MXenen 
monolayer with its repeated images along the $\mathrm{z}$ axis, we set the height of supercell to $35 \AA$ with the vacuum thickness of more than $25 \AA$ here.

$\mathbf{n}=\mathbf{1}$

(a)

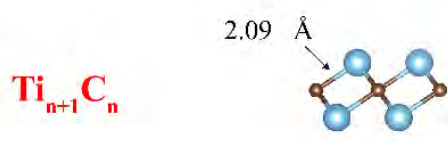

(b)

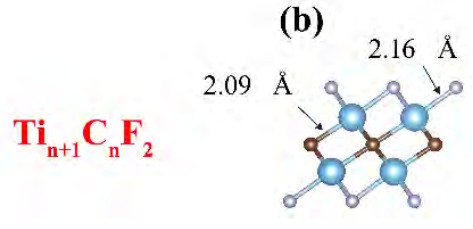

(c)

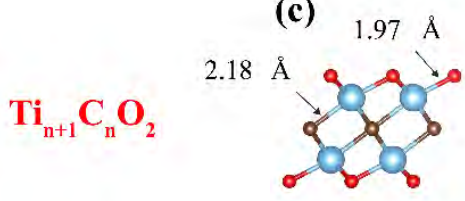

(d)

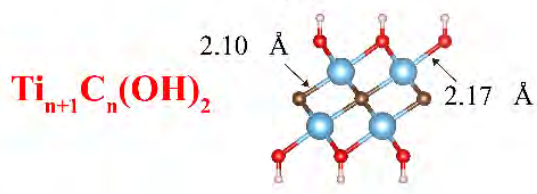

$\mathbf{n}=\mathbf{2}$

(e)

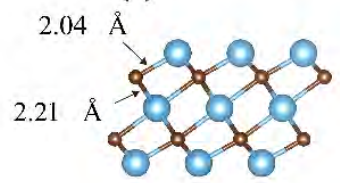

(f) $2.15 \AA$

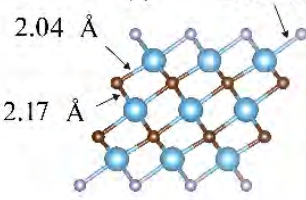

(g)

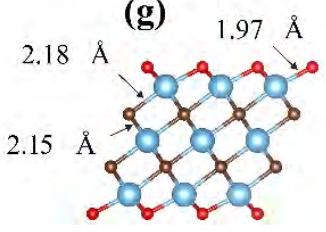

(h)

$\mathbf{n}=\mathbf{3}$

(i)

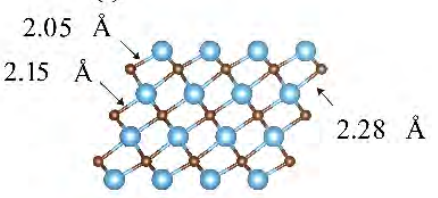

(j) $\quad 2.17 \AA$

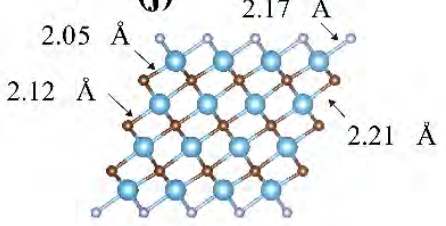

(k)

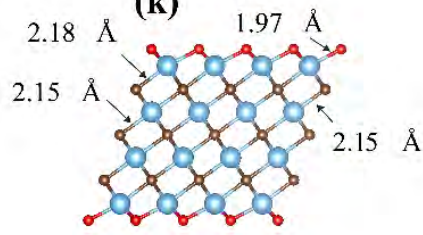

(I)

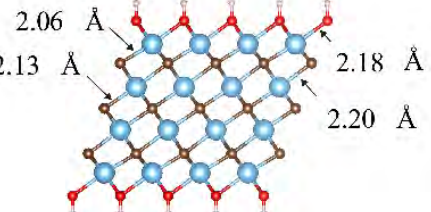

Figure 1. Models of $2 \mathrm{D} \mathrm{Ti}_{\mathrm{n}+1} \mathrm{C}_{\mathrm{n}}$ and functionalized $\mathrm{Ti}_{\mathrm{n}+1} \mathrm{C}_{\mathrm{n}} \mathrm{T}_{2}(\mathrm{~T}=-\mathrm{F},-\mathrm{O},-\mathrm{OH} ; \mathrm{n}=1,2,3)$ and the calculated equilibrium inter-atomic distances in $\AA$. Color code: Titanium, blue;

Carbon, brown; Fluorine, grey; Oxygen, red; and Hydrogen, pink.

The optimized lattice constant of $2 \mathrm{D} \mathrm{Ti} i_{n+1} \mathrm{C}_{n}$ and $\mathrm{Ti}_{\mathrm{n}+1} \mathrm{C}_{\mathrm{n}} \mathrm{T}_{2}(\mathrm{~T}=-\mathrm{F},-\mathrm{O}$, or $-\mathrm{OH} ; \mathrm{n}=$ 1, 2, or 3) are listed in Table S2 along with the reported data. The similarity between our results and the reported data justifies the choice of the parameters used in this study. Fig. 1 illustrates the atomic models of $2 \mathrm{D} \mathrm{Ti} i_{n+1} C_{n}(a, e$ and $i)$ and the corresponding $\mathrm{Ti}_{n+1} \mathrm{C}_{\mathrm{n}} \mathrm{T}_{2}$ systems $(\mathrm{b}, \mathrm{c}, \mathrm{d}$, f, g, h, j, k and l). The relevant bond lengths are also provided in Fig. 1. It reveals that the Ti$\mathrm{C}$ bond lengths in the outmost layer increased after the surface functionalization in all the $\mathrm{Ti}_{n+1} \mathrm{C}_{n}$ ( $\mathrm{n}=1$, 2 or 3 ). However, the extent of the change of the corresponding Ti-C bond length is greatly affected by the terminal groups. The slight changes of $\mathrm{Ti}-\mathrm{C}$ bond length in the systems with the $-\mathrm{OH}$ and $-\mathrm{F}$ (less than $0.04 \AA$ ) suggest the weak impact of these terminal groups on the structural properties. As a comparison, the corresponding Ti-C bond length 
increased by $\sim 0.1 \AA$ when the terminal group is -O. It, therefore, indicates a relatively strong interaction between the surface $\mathrm{Ti}$ atoms and the $-\mathrm{O}$ terminal group. This matches the recent DFT results conducted by Fu et al. that the $-\mathrm{O}$ terminal group can most significantly stabilize the $\mathrm{Ti}_{3} \mathrm{C}_{2}$ due to the strongest interaction energies in terms to those of $-\mathrm{OH}$ and $-\mathrm{F}$ terminal groups [21]. The stronger interaction between the surface $\mathrm{Ti}$ atoms and the $-\mathrm{O}$ terminal group is also supported by the shortest Ti-T bond length in terms to other surface functionalized systems.

The total density of states (TDOS) of $\mathrm{Ti}_{n+1} \mathrm{C}_{n}$ and $\mathrm{Ti}_{\mathrm{n}+1} \mathrm{C}_{\mathrm{n}} \mathrm{T}_{2}(\mathrm{~T}=-\mathrm{F},-\mathrm{O},-\mathrm{OH} ; \mathrm{n}=1$, 2, 3) are shown in Fig. 2a-c, which also agree with the reported data [32]. Almost all the systems show the metallic properties except $\mathrm{Ti}_{2} \mathrm{CO}_{2}$. However, the evolution at the Fermi energy level shifts downwards after the surface functionalization. The biggest shift was observed after the $-\mathrm{O}$ surface functionalization, followed by $-\mathrm{F}$ and the $-\mathrm{OH}$. This trend of the shift amount is the same as the change of structural properties of $\mathrm{Ti}_{n+1} \mathrm{C}_{n} \mathrm{~T}_{2}$. It confirms that the -O terminal groups have the strongest interaction with the surface Ti atoms, which change the electronic properties of the systems most significantly. The adsorption energies of the different terminal group on $\mathrm{Ti}_{\mathrm{n}+1} \mathrm{C}_{\mathrm{n}}$ are also calculated, which are listed in Table S3. Our results again greatly match previous data [21]. The -O terminal group has the strongest interaction with all $\mathrm{Ti}_{\mathrm{n}+1} \mathrm{C}_{\mathrm{n}}$. It confirms the deduction through the analyses of the structural and electronic properties of $\mathrm{Ti}_{n+1} \mathrm{C}_{n} \mathrm{~T}_{2}(\mathrm{~T}=-\mathrm{F},-\mathrm{O},-\mathrm{OH} ; \mathrm{n}=1,2,3)$. Moreover, the band structure of the most stable $\mathrm{Ti}_{4} \mathrm{C}_{3} \mathrm{O}_{2}$ is shown in Fig. 2d. 
(a)

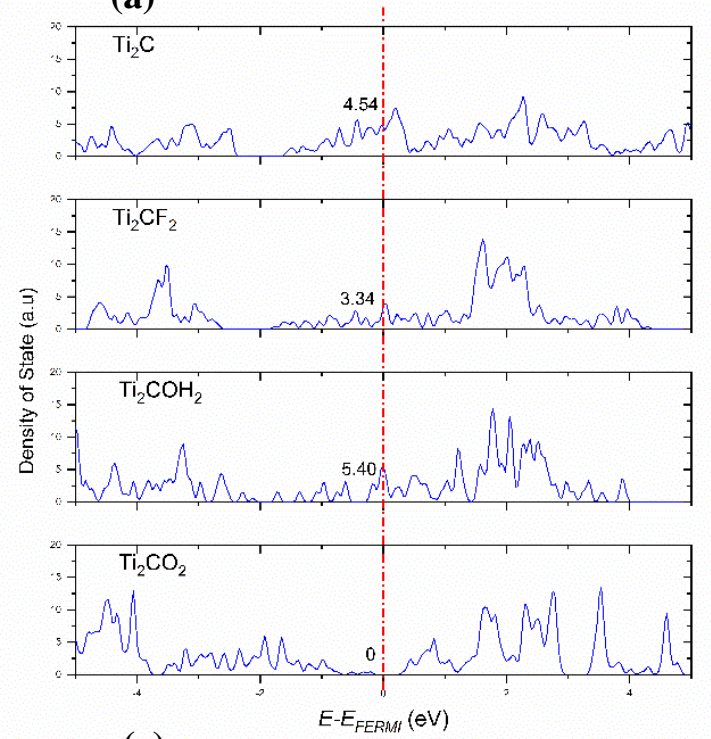

(c)

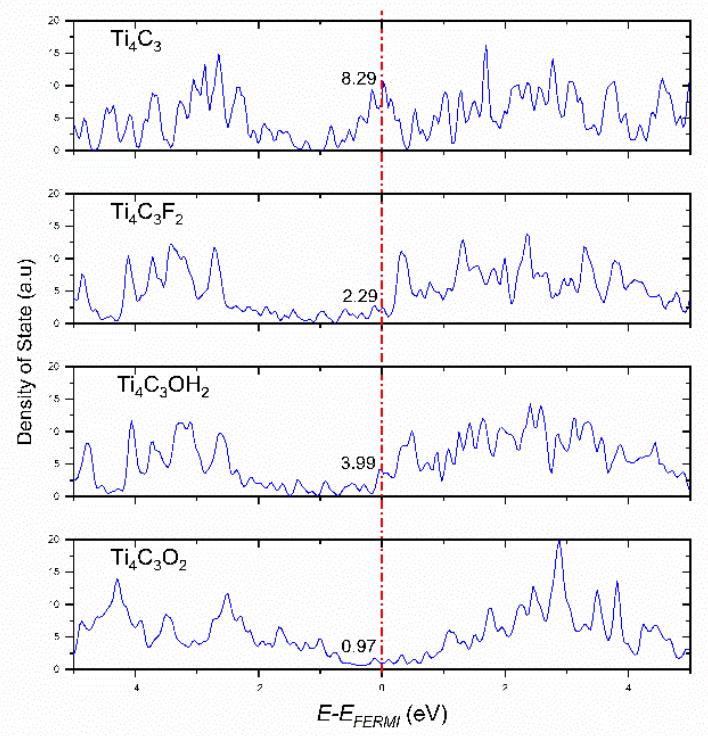

(b)
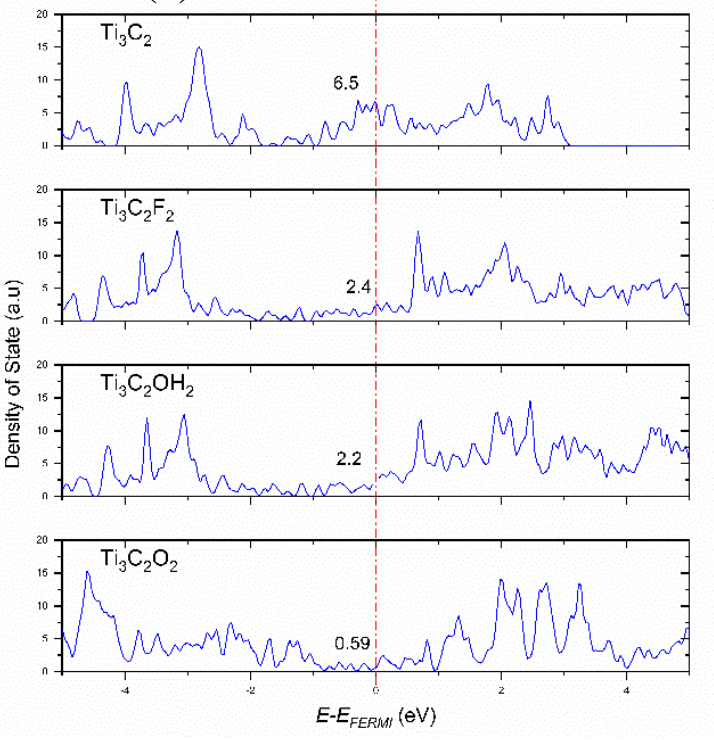

(d)

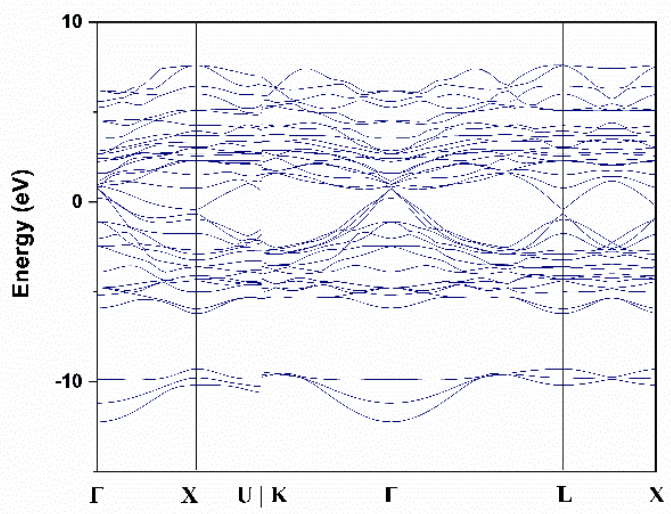

Figure 2. Densities of states (DOS) of (a) $\mathrm{Ti}_{2} \mathrm{C}$ and $\mathrm{Ti}_{2} \mathrm{CT}_{2}$, (b) $\mathrm{Ti} 3 \mathrm{C} 2$ and $\mathrm{Ti}_{3} \mathrm{C}_{2} \mathrm{~T}_{2}$, (c) $\mathrm{Ti}_{4} \mathrm{C} 3$ and $\mathrm{Ti}_{4} \mathrm{C}_{3} \mathrm{~T}_{2}(\mathrm{~T}=-\mathrm{F},-\mathrm{O},-\mathrm{OH})$ monolayers along with the corresponding evolution at the Fermi energy level and (d) band structure of $\mathrm{Ti}_{4} \mathrm{C}_{3} \mathrm{O}_{2}$.

After understanding the influences of the termination groups on the structural and electronic properties, their impacts on the mechanical strengths are systematically studied through calculating the elastic constants based on the strain-energy method. There are two types of the elastic constants for 2D materials; in-plane planar elastic constants in $\mathrm{N} \mathrm{m}^{-1}$ and in-plane bulk elastic constants in GPa. Since the calculation of in-plane bulk elastic constants faces the challenge to define reasonable thickness of the monolayer, only the in-plane planar elastic constants and other in-plane planar mechanical properties are discussed here. For 
comparison, the calculated in-plane planar elastic constants $C_{i j}$ are listed in Table $\mathbf{1}$. The results for $\mathrm{Ti}_{3} \mathrm{C}_{2} \mathrm{~T}_{2}$ are in a very good agreement with the reported DFT data [22]. $\mathrm{Ti}_{2} \mathrm{C}$ properties are also similar to the previous first principles results [20]. Therefore, it can be concluded that the present DFT method is able to provide reliable results for this new $T i_{n+1} C_{n}$ and $T_{n+1} C_{n} T_{2}$ MXenes family.

Table 1. Calculated in-plane planar elastic constants $C_{11}, C_{22}, C_{12}$ and $C_{66}\left(N^{-1}\right)$ of $T_{n+1} C_{n}$ and $\mathrm{Ti}_{\mathrm{n}+1} \mathrm{C}_{\mathrm{n}} \mathrm{T}_{2}(\mathrm{~T}=-\mathrm{F},-\mathrm{O}$, or $-\mathrm{OH} ; \mathrm{n}=1$, 2, or 3 ) monolayers in comparison with previously reported data from the literature (inside the brackets).

\begin{tabular}{|c|c|c|c|c|}
\hline & $\mathrm{C}_{11}\left(\mathrm{~N} \mathrm{~m}^{-1}\right)$ & $\mathrm{C}_{22}\left(\mathrm{~N} \mathrm{~m}^{-1}\right)$ & $\mathrm{C}_{12}\left(\mathrm{~N} \mathrm{~m}^{-1}\right)$ & $\mathrm{C}_{66}\left(\mathrm{~N} \mathrm{~m}^{-1}\right)$ \\
\hline $\mathrm{Ti}_{2} \mathrm{C}$ & 151 (137[20]) & 153 & 35 (32[20]) & 54 \\
\hline $\mathrm{Ti}_{2} \mathrm{CO}_{2}$ & 272 & 274 & 81 & 98 \\
\hline $\mathrm{Ti}_{2} \mathrm{CF}_{2}$ & 172 & 175 & 77 & 56 \\
\hline $\mathrm{Ti}_{2} \mathrm{C}(\mathrm{OH})_{2}$ & 173 & 176 & 48 & 67 \\
\hline $\mathrm{Ti}_{3} \mathrm{C}_{2}$ & 253 (241[21]) & 257 & 40 & 105 \\
\hline $\mathrm{Ti}_{3} \mathrm{C}_{2} \mathrm{O}_{2}$ & $392(379[21])$ & 398 & 101 & 145 \\
\hline $\mathrm{Ti}_{3} \mathrm{C}_{2} \mathrm{~F}_{2}$ & $322(316[21])$ & 322 & 80 & 127 \\
\hline $\mathrm{Ti}_{3} \mathrm{C}_{2}(\mathrm{OH})_{2}$ & $332(282[21])$ & 335 & 74 & 133 \\
\hline $\mathrm{Ti}_{4} \mathrm{C}_{3}$ & 312 & 306 & 49 & 132 \\
\hline $\mathrm{Ti}_{4} \mathrm{C}_{3} \mathrm{O}_{2}$ & 521 & 518 & 126 & 196 \\
\hline $\mathrm{Ti}_{4} \mathrm{C}_{3} \mathrm{~F}_{2}$ & 458 & 456 & 97 & 178 \\
\hline $\mathrm{Ti}_{4} \mathrm{C}_{3}(\mathrm{OH})_{2}$ & 443 & 445 & 100 & 176 \\
\hline
\end{tabular}

The in-plane planar Young's and shear moduli, Poisson's ratio of $\mathrm{Ti}_{\mathrm{n}+1} \mathrm{C}_{\mathrm{n}}$ and $\mathrm{Ti}_{\mathrm{n}+1} \mathrm{C}_{n} \mathrm{~T}_{2}$ ( $\mathrm{T}=-\mathrm{F},-\mathrm{O}$, or $-\mathrm{OH} ; \mathrm{n}=1,2$, or 3 ) monolayer can, then, be derived from the in-plane planar elastic constants as:

$$
\begin{aligned}
& v_{x y}^{2 D}=\frac{C_{21}}{C_{22}}, \quad v_{y x}^{2 D}=\frac{C_{12}}{C_{11}}, \\
& E_{x}^{2 D}=\frac{C_{11} C_{22}-C_{12} C_{21}}{C_{22}}, \quad E_{y}^{2 D}=\frac{C_{11} C_{22}-C_{12} C_{21}}{C_{11}}, \quad G_{y x}^{2 D}=C_{66}
\end{aligned}
$$

The calculated in-plane planar Poisson's ratio, Young's and shear moduli, values are listed in Table 2. The Poisson's ratio reflects the mechanical ductility and flexibility. Our results are close to the reported data listed in the brackets in Table 2 except those of $\mathrm{Ti}_{3} \mathrm{C} 2$ and $\mathrm{Ti}_{3} \mathrm{C}_{2}(\mathrm{OH})_{2}$. In our study, the Poisson's ratio of $\mathrm{Ti}_{3} \mathrm{C}_{2} \mathrm{O}_{2}$ was $65 \%$ higher than that of $\mathrm{Ti}_{3} \mathrm{C}_{2}$, which is close to the corresponding value of $66 \%$ reported in the same paper [21]. The similar $v_{x y}^{2 D}$ and $v_{y x}^{2 D}$ values suggest that $\mathrm{Ti}_{\mathrm{n}+1} \mathrm{C}_{\mathrm{n}}$ and $\mathrm{Ti}_{\mathrm{n}+1} \mathrm{C}_{\mathrm{n}} \mathrm{T}_{2}$ have the isotropic mechanical properties. The Poisson's ratios of $\mathrm{Ti}_{n+1} \mathrm{C}_{n}$ are increased after the surface functionalization, which suggest the better ductility and flexibility caused by the adsorption of the terminal groups. Interestingly, there is no clear change trend of in-plane Poisson's ratios caused by the thickness and the terminal groups. Additionally, the variance of in-plane Poisson's ratios of all $\mathrm{Ti}_{n+1} \mathrm{C}_{n} \mathrm{~T}_{2}$ is also 
small (0.212-0.450). The biggest Poisson's ratio is found in $\mathrm{Ti}_{2} \mathrm{CF}_{2}$, which suggest that $\mathrm{Ti}_{2} \mathrm{CF}_{2}$ is more flexible than other $\mathrm{Ti}_{n+1} \mathrm{C}_{n}$ and $\mathrm{Ti}_{n+1} \mathrm{C}_{n} \mathrm{~T}_{2}$ materials.

Table 2. Calculated in-plane planar Young's and shear moduli $\left(\mathrm{N} \mathrm{m}^{-1}\right)$, and Poisson's ratio of $\mathrm{Ti}_{\mathrm{n}+1} \mathrm{C}_{\mathrm{n}}$ and $\mathrm{Ti}_{\mathrm{n}+1} \mathrm{C}_{\mathrm{n}} \mathrm{T}_{2}(\mathrm{~T}=-\mathrm{F},-\mathrm{O}$, or $-\mathrm{OH} ; \mathrm{n}=1$, 2 , or 3 ) monolayers in comparison with previously reported data from the literature (inside the brackets).

\begin{tabular}{lccccc}
\hline & $\boldsymbol{v}_{\boldsymbol{x y}}^{2 \boldsymbol{D}}$ & $\boldsymbol{v}_{\boldsymbol{y} \boldsymbol{x}}^{\mathbf{D}}$ & $\boldsymbol{E}_{\boldsymbol{x}}^{\mathbf{2 D}}\left(\mathbf{N ~ m}^{-\mathbf{1}}\right)$ & $\boldsymbol{E}_{\boldsymbol{y}}^{\mathbf{2 D}}\left(\mathbf{N ~ m}^{\mathbf{- 1}}\right)$ & $\boldsymbol{G}_{\boldsymbol{x y}}^{\mathbf{2 D}}\left(\mathbf{N ~ m}^{\mathbf{- 1}}\right)$ \\
\hline $\mathrm{Ti}_{2} \mathrm{C}$ & $0.231(0.23[20])$ & $0.233(0.23[20])$ & $143(130[20])$ & $144(130[20])$ & 54 \\
$\mathrm{Ti}_{2} \mathrm{CO}_{2}$ & 0.296 & 0.298 & 248 & 250 & 98 \\
$\mathrm{Ti}_{2} \mathrm{CF}_{2}$ & 0.443 & 0.450 & 138 & 140 & 56 \\
$\mathrm{Ti}_{2} \mathrm{C}(\mathrm{OH})_{2}$ & 0.274 & 0.278 & 160 & 162 & 67 \\
\hline $\mathrm{Ti}_{3} \mathrm{C}_{2}$ & $0.154(0.227[21])$ & $0.156(0.226[21])$ & $247(228[21])$ & $251(227[21])$ & $105(103[21])$ \\
$\mathrm{Ti}_{3} \mathrm{C}_{2} \mathrm{O}_{2}$ & $0.254(0.291[21])$ & $0.258(0.291[21])$ & $366(347)$ & $372(347[21])$ & $145(135[21])$ \\
$\mathrm{Ti}_{3} \mathrm{C}_{2} \mathrm{~F}_{2}$ & $0.247(0.258[21])$ & $0.247(0.258[21])$ & $302(295)$ & $303(293[21])$ & $127(119[21])$ \\
$\mathrm{Ti}_{3} \mathrm{C}_{2}(\mathrm{OH})_{2}$ & $0.220(0.304[21])$ & $0.222(0.309[21])$ & $316(256)$ & $319(260[21])$ & $133(101[21])$ \\
\hline $\mathrm{Ti}_{4} \mathrm{C}_{3}$ & 0.159 & 0.155 & 305 & 298 & 132 \\
$\mathrm{Ti}_{4} \mathrm{C}_{3} \mathrm{O}_{2}$ & 0.243 & 0.242 & 490 & 488 & 196 \\
$\mathrm{Ti}_{4} \mathrm{C}_{3} \mathrm{~F}_{2}$ & 0.213 & 0.212 & 437 & 436 & 178 \\
$\mathrm{Ti}_{4} \mathrm{C}_{3}(\mathrm{OH})_{2}$ & 0.224 & 0.225 & 420 & 422 & 176 \\
\hline
\end{tabular}

The difference of the in-plane plane Young's moduli along the tension axis $\mathrm{x}$ and $\mathrm{y}$ directions are also almost identical. The variance is less than $7 \mathrm{~N} \mathrm{~m}^{-1}$. Again, it supports that both $\mathrm{Ti}_{n+1} \mathrm{C}_{\mathrm{n}}$ and $\mathrm{Ti}_{\mathrm{n}+1} \mathrm{C}_{\mathrm{n}} \mathrm{T}_{2}$ exhibit good isotropy. As such, we use the $E_{x}^{2 D}$ values for comparison here. The calculated $E_{x}^{2 D}$ of $\mathrm{Ti}_{\mathrm{n}+1} \mathrm{C}_{\mathrm{n}}\left(\mathrm{n}=1,2\right.$ or 3 ) are 143, 243 and $305 \mathrm{~N} \mathrm{~m}^{-1}$, respectively. It suggests that the in-plane Young's moduli of $\mathrm{Ti}_{\mathrm{n}+1} \mathrm{C}_{\mathrm{n}}$ increase over the monolayer thickness (by increasing the $n$ value of $\mathrm{Ti}_{\mathrm{n}+1} \mathrm{C}_{\mathrm{n}}$ ). The same trend was reported by the previous investigations in a comprehensive first principles study of $\mathrm{Ti}_{n+1} \mathrm{C}_{n}$ [32, 33]. Young's modulus is a parameter representing the stiffness of a solid. Our results suggest that the stiffness of both $\mathrm{Ti}_{n+1} \mathrm{C}_{n}$ and $\mathrm{Ti}_{n+1} \mathrm{C}_{n} T_{2}$ is strengthened with the increase of their $\mathrm{n}$ value or thickness of the monolayer. Furthermore, the current study demonstrates that all the termination groups improve the stiffness of $\mathrm{Ti}_{n+1} \mathrm{C}_{n}$. This is because Young's modulus is a function of atomic bond strength. The strong adsorption energy of the terminal groups can effectively enhance the overall atomic bond strength, which leads to the improved Young's moduli after the surface functionalization. Moreover, the functionalization by -O terminal group leads to the largest enhancement of the Young's moduli, which can be ascribed to the strongest interaction between $\mathrm{Ti}_{n+1} \mathrm{C}_{\mathrm{n}}$ and the $-\mathrm{O}$ terminal group in terms to $-\mathrm{OH}$ and $-\mathrm{F}$ (see Table S3). Consequently, $\mathrm{Ti}_{4} \mathrm{C}_{3} \mathrm{O}_{2}$ has the largest in-plane planar Young's modulus (490 and $488 \mathrm{~N} \mathrm{~m}^{-1}$ in the $\mathrm{x}$ and $\mathrm{y}$ directions, respectively) due to the combined influences of the thickness of the monolayer and the terminal groups. Accordingly, the in-plane planar shear moduli show a similar trend over the thickness of the monolayer and the terminal groups. The 
in-plane share modules represent the plastic deformation of a 2D material. As such, the $\mathrm{Ti}_{4} \mathrm{C}_{3} \mathrm{O}_{2}$, which exhibits the largest $G_{x y}^{2 D}$ value of $196 \mathrm{~N} \mathrm{~m}^{-1}$, has the largest resistant to shape change.

Graphene was once regarded as the strongest materials known due to its large Young's modulus ( 1TPa and $\sim 340 \mathrm{~N} \mathrm{~m}^{-1}$ for in-plane bulk and planar Young's moduli, respectively) [34]. The recent experiments demonstrate that the $\mathrm{Ti}_{3} \mathrm{C}_{2} \mathrm{~T}_{2}$ has the comparable in-plane planar Young's modulus (337 $\left.\pm 35 \mathrm{~N} \mathrm{~m}^{-1}\right)$. Based on our calculations, it can be found that the in-plane planar Young's modulus can be further improved by increasing the $n$ value from 2 to 3 in $\mathrm{Ti}_{\mathrm{n}+1} \mathrm{C}_{\mathrm{n}} \mathrm{T}_{2}$. As such, all the surface functionalized $\mathrm{Ti}_{4} \mathrm{C}_{3} \mathrm{~T}_{2}$ exhibit the in-plane planar Young's moduli higher than $400 \mathrm{~N} \mathrm{~m}^{-1}$ along both the tension axis $\mathrm{x}$ and y directions, as shown in Fig. 3a and $\mathbf{b}$. Specifically, the $\mathrm{Ti}_{4} \mathrm{C}_{3} \mathrm{~T}_{2}$ has the largest in-plane planar Young's modulus among all systems considered here, which is about $40 \%$ higher than that of graphene. As evidenced by Fig. 3c, $\mathrm{Ti}_{4} \mathrm{C}_{3}$ and $\mathrm{Ti}_{4} \mathrm{C}_{3} \mathrm{~T}_{2}$ also have a larger in-plane shear moduli in terms to that of graphene ( $140 \mathrm{~N} \mathrm{~m}^{-1}$ ) [34]. Additionally, the Poisson's ratios of all the $\mathrm{Ti}_{4} \mathrm{C}_{3} \mathrm{~T}_{2}(0.21-0.24)$ are similar as that of the graphene $(\sim 0.24)$. It suggests that they have the similar mechanical ductility and flexibility. To this end, all $\mathrm{Ti}_{4} \mathrm{C}_{3} \mathrm{~T}_{2}$, especially $\mathrm{Ti}_{4} \mathrm{C}_{3} \mathrm{O}_{2}$, are promising materials for the applications that requires 2D materials with superior mechanical properties.

(a)

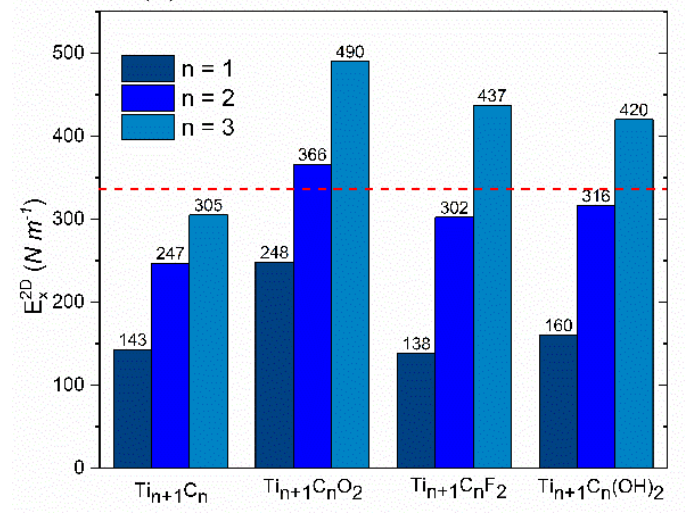

(b)

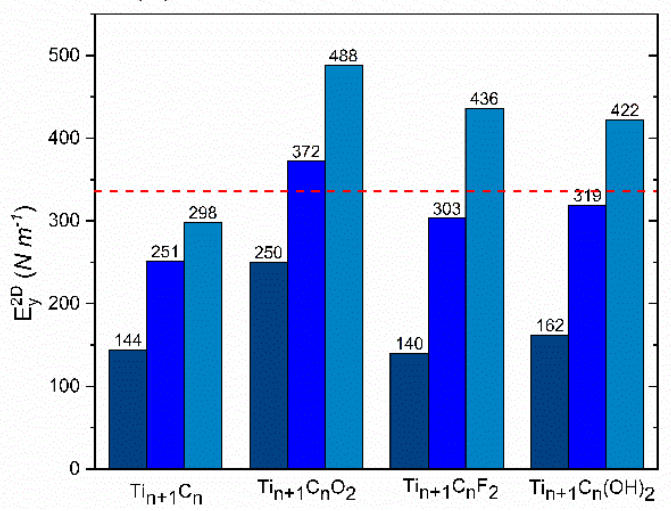

(c)

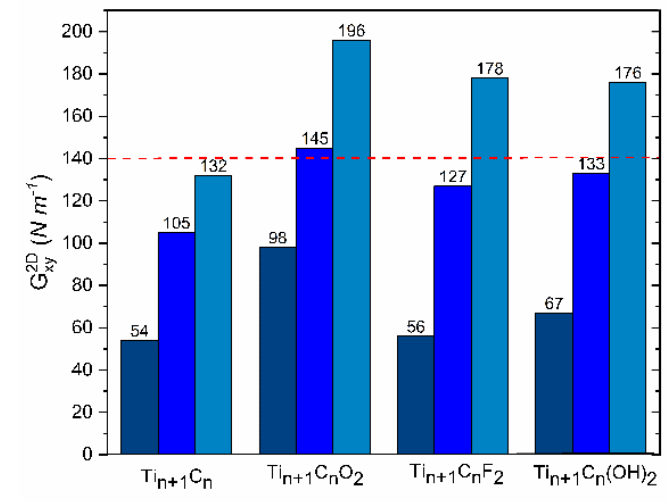


Figure 3. (a) In-plane Young's moduli $\mathrm{E}^{2 \mathrm{D}}\left(\mathrm{N} \mathrm{m}^{-1}\right)$ in $\mathrm{x}$ direction, (b) in-plane Young's moduli $\mathrm{E}^{2 \mathrm{D}}\left(\mathrm{N} \mathrm{m}^{-1}\right)$ in y direction and (c) in-plane shear moduli of bare $2 \mathrm{D} \mathrm{Ti}_{\mathrm{n}+1} \mathrm{C}_{\mathrm{n}}(\mathrm{n}=1,2$, 3) and functionalized $\mathrm{Ti}_{n+1} \mathrm{C}_{n} \mathrm{~T}_{2}(\mathrm{~T}=-\mathrm{F},-\mathrm{O},-\mathrm{OH} ; \mathrm{n}=1,2,3)$ monolayers. The red dotted lines show the corresponding values of graphene.

In summary, our first-principles DFT calculations have been conducted to systematically investigate the mechanical properties of $T_{n+1} C_{n}$ and $T_{n+1} C_{n} T_{2}(T=-F,-O$, or $-\mathrm{OH} ; \mathrm{n}=1$, 2, or 3). It is found the Poisson's ratio increase after the surface functionalization. However, the change of Poison's ration is almost independent to the $n$ value of $\operatorname{Ti}_{n+1} C_{n}$ and terminal groups. As a comparison, the significant dependence of the in-plane planar Young's and shear moduli on the $n$ value has been theoretically identified. $T i_{n+1} C_{n}$ and $T i_{n+1} C_{n} T_{2}$ become stiffer with the increase of the $\mathrm{n}$ value. Additionally, the larger interaction between the $-\mathrm{O}$ terminal group with the $\mathrm{Ti}_{\mathrm{n}+1} \mathrm{C}_{\mathrm{n}}$ leads to $-\mathrm{O}$ functionalized MXene exhibit stronger mechanical properties. Consequently, $\mathrm{Ti}_{4} \mathrm{C}_{3} \mathrm{O}_{2}$ is the strongest material among all the considered systems. More importantly, all $\mathrm{Ti}_{4} \mathrm{C}_{3} \mathrm{~T}_{2}$ have larger n-plane planar Young's and shear moduli in terms to those of graphene, which was once thought to be the strongest materials known. As such, $\mathrm{Ti}_{4} \mathrm{C}_{3} \mathrm{~T}_{2}$ can be the alternative to graphene for the applications which need 2D materials with considerably high stiffness and large resistant to shape change. It is worth noting that the recent theoretical study reveals more possible surface-functionalized MXene configurations, especially with the Janus characteristics.[35] To this end, the comprehensive studies on the impact of different metal, non-metal and terminal groups will be imperative to identical materials with the desired mechanical properties.

\section{Acknowledgements}

This work was supported by the Australian Research Council (DP 170104834). This research was undertaken on the supercomputers in National Computational Infrastructure (NCI) in Canberra, Australia, which is supported by the Australian Commonwealth Government, and Pawsey Supercomputing Centre in Perth with the funding from the Australian government and the Government of Western Australia.

\section{References}

Born M and Huang K 1954 Dynamical theory of crystal lattices: Clarendon press) 
[2] Loh K P, Bao Q, Ang P K and Yang J 2010 The chemistry of graphene J. Mater. Chem. 20 227789

[3] Gogotsi Y 2011 Controlling Graphene Properties Through Chemistry J. Phys. Chem. Lett. 2 2509-10

[4] Akinwande D, Brennan C J, Bunch J S, Egberts P, Felts J R, Gao H, Huang R, Kim J-S, Li T, Li Y, Liechti K M, Lu N, Park H S, Reed E J, Wang P, Yakobson B I, Zhang T, Zhang Y-W, Zhou Y and Zhu $Y 2017$ A review on mechanics and mechanical properties of 2D materials-Graphene and beyond Extreme Mech. Lett. 13 42-77

[5] Barsoum M W 2013 MAX phases: properties of machinable ternary carbides and nitrides: John Wiley \& Sons)

[6] Naguib M, Mochalin V N, Barsoum M W and Gogotsi Y 2014 25th anniversary article: MXenes: a new family of two-dimensional materials Adv. Mater. 26 992-1005

[7] Salama I, El-Raghy T and Barsoum M 2002 Synthesis and mechanical properties of Nb2AIC and (Ti, Nb) 2AIC J. Alloys Compd. 347 271-8

[8] Zha X-H, Huang Q, He J, He H, Zhai J, Francisco J S and Du S 2016 The thermal and electrical properties of the promising semiconductor MXene Hf 2 CO 2 Sci. Rep. 627971

[9] Luo J, Tao X, Zhang J, Xia Y, Huang H, Zhang L, Gan Y, Liang C and Zhang W 2016 Sn4+ ion decorated highly conductive Ti3C2 MXene: promising lithium-ion anodes with enhanced volumetric capacity and cyclic performance Acs Nano 10 2491-9

[10] Anasori B, Lukatskaya M R and Gogotsi Y 2017 2D metal carbides and nitrides (MXenes) for energy storage Nat. Rev. Mater. 216098

[11] Shahzad F, Alhabeb M, Hatter C B, Anasori B, Hong S M, Koo C M and Gogotsi Y 2016 Electromagnetic interference shielding with 2D transition metal carbides (MXenes) Science 353 1137-40

[12] Lukatskaya M R, Kota S, Lin Z, Zhao M-Q, Shpigel N, Levi M D, Halim J, Taberna P-L, Barsoum M W and Simon P 2017 Ultra-high-rate pseudocapacitive energy storage in two-dimensional transition metal carbides Nat. Energy 217105

[13] Feng W, Luo H, Wang Y, Zeng S, Tan Y, Deng L, Zhou X, Zhang H and Peng S 2019 Mxenes Derived Laminated and Magnetic Composites with Excellent Microwave Absorbing Performance Sci. Rep. 93957

[14] Gao G, O'Mullane A P and Du A 2016 2D MXenes: a new family of promising catalysts for the hydrogen evolution reaction ACS Catal. 7 494-500

[15] Ma Y, Liu N, Li L, Hu X, Zou Z, Wang J, Luo S and Gao Y 2017 A highly flexible and sensitive piezoresistive sensor based on MXene with greatly changed interlayer distances Nat. Commun. 81207

[16] Lipatov A, Alhabeb M, Lukatskaya M R, Boson A, Gogotsi Y and Sinitskii A 2016 Effect of synthesis on quality, electronic properties and environmental stability of individual monolayer Ti3C2 MXene flakes Adv. Electron. Mater. 21600255

[17] Liu L, Wu J, Wu L, Ye M, Liu X, Wang Q, Hou S, Lu P, Sun L and Zheng J 2018 Phase-selective synthesis of $1 T^{\prime}$ MoS 2 monolayers and heterophase bilayers Nat. Mater. 171108

[18] Wang L, Xu X, Zhang L, Qiao R, Wu M, Wang Z, Zhang S, Liang J, Zhang Z and Zhang Z 2019 Epitaxial growth of a 100-square-centimetre single-crystal hexagonal boron nitride monolayer on copper Nature $\mathbf{5 7 0} 91$

[19] Kurtoglu M, Naguib M, Gogotsi Y and Barsoum M W 2012 First principles study of twodimensional early transition metal carbides MRS Commun. 2 133-7

[20] Wang S, Li J-X, Du Y-L and Cui C 2014 First-principles study on structural, electronic and elastic properties of graphene-like hexagonal Ti2C monolayer Comput. Mater. Sci. 83 290-3

[21] Fu Z, Zhang Q, Legut D, Si C, Germann T, Lookman T, Du S, Francisco J and Zhang R 2016 Stabilization and strengthening effects of functional groups in two-dimensional titanium carbide Phys. Rev. B 94104103 
[22] Lipatov A, Lu H, Alhabeb M, Anasori B, Gruverman A, Gogotsi Y and Sinitskii A 2018 Elastic properties of 2D Ti3C2Tx MXene monolayers and bilayers Sci. Adv. 4 eaat0491

[23] Cao W-T, Feng W, Jiang Y-Y, Ma C, Zhou Z-F, Ma M-G, Chen Y and Chen F 2019 Twodimensional MXene-reinforced robust surface superhydrophobicity with self-cleaning and photothermal-actuating binary effects Mater. Horiz. 6 1057-65

[24] Kresse G and Furthmüller J 1996 Software VASP, vienna (1999) Phys. Rev. B 54169

[25] Kresse G and Joubert D 1999 From Ultrasoft Pseudopotentials to the Projector AugmentedWave Method Phys. Rev. B: Condens. Matter 59 1758-75

[26] Perdew J P, Burke K and Ernzerhof M 1996 Generalized gradient approximation made simple Phys. Rev. Lett. 773865

[27] Klimes J and Michaelides A 2012 Perspective: Advances and challenges in treating van der Waals dispersion forces in density functional theory J. Chem. Phys. 137

[28] Sun T, Wang Y, Zhang H M, Liu P R and Zhao H J 2015 Adsorption and oxidation of oxalic acid on anatase TiO2 (001) surface: A density functional theory study J. Colloid Interface Sci. 454 180-6

[29] Grimme S, Antony J, Ehrlich S and Krieg H 2010 A consistent and accurate ab initio parametrization of density functional dispersion correction (DFT-D) for the 94 elements $\mathrm{H}-\mathrm{Pu}$ J. Chem. Phys. 132154104

[30] Akgenc B, Kinaci A, Tasseven C and Cagin T 2018 First - principles calculations on stability and mechanical properties of various ABO3 and their alloys Mater. Chem. Phys. 205 315-24

[31] Wang V and Geng W T 2017 Lattice Defects and the Mechanical Anisotropy of Borophene J. Phys. Chem. C 121 10224-32

[32] Zhang N, Hong $Y$, Yazdanparast S and Zaeem M A 2018 Superior structural, elastic and electronic properties of 2D titanium nitride MXenes over carbide MXenes: a comprehensive first principles study 2D Mater. 5045004

[33] Guo Z, Zhou J, Si C and Sun Z 2015 Flexible two-dimensional Ti n+ 1 C n ( $n=1,2$ and 3) and their functionalized MXenes predicted by density functional theories Phys. Chem. Chem. Phys. 17 15348-54

[34] Lee C, Wei X, Kysar J W and Hone J 2008 Measurement of the elastic properties and intrinsic strength of monolayer graphene Science 321 385-8

[35] Akgenc B 2020 Intriguing of two-dimensional Janus surface-functionalized MXenes: An ab initio calculation Comput. Mater. Sci. 171 